\title{
Neonatal Seizures: Frequency, Clinical Forms, Aetiology and Outcome in Tropical Practice
}

\author{
Bahoura Balaka ${ }^{1}$, Komi Assogba ${ }^{2,}$, Fidato A. Touglo ${ }^{1}$, Damelan Kombaté2, Kossivi M. Apetsè ${ }^{2}$, \\ Marie C. Ayassou-Madji
}

${ }^{1}$ Neonatology units, paediatrics University Hospital, CHUSO, Lomé, Togo

${ }^{2}$ Neurology departments, Campus University Hospital, Lomé, Togo

\section{Email address:}

seraphinassogba@hotmail.com (K. Assogba)

\section{To cite this article:}

Bahoura Balaka, Komi Assogba, Fidato A. Touglo, Damelan Kombaté, Kossivi M. Apetsè, Marie C. Ayassou-Madji. Neonatal Seizures: Frequency, Clinical Forms, Aetiology and Outcome in Tropical Practice. American Journal of Psychiatry and Neuroscience. Special Issue: Clinical Neurosciences in Tropical Practice. Vol. 3, No. 5-1, 2015, pp. 1-4. doi: 10.11648/j.ajpn.s.2015030501.11

\begin{abstract}
Background: Seizures are common cause of paediatric admissions in poor resource countries and a risk factor for neurodevelopmental impairment. This study aimed to determine the frequency, clinical forms, aetiology and outcome of seizures in relation to rectal temperature in newborn. Patients and Methods: The study was located in paediatric department of our University Hospital. This prospective research had assessed consecutive admitted newborns aged 0-28 days with incident seizure during a period from January to December, 2013. Newborns with epilepsy and non-incident admission seizure were excluded. Results: Seizures were observed in 344/4836 (7.1\%). The sample included 192 males and 152 females. The seizures frequency in newborn 0-21 days was $95.9 \%$ and was $52.6 \%$ in neonates $<1$ day. The focal seizures were reported in $68 \%$ follow by generalized tonic-clonic in $24.4 \%$. Status epilepticus was observed in $7.6 \%$. Seizures had occurred in a context of hypothermia in $77.9 \%$, normal temperature, $14.2 \%$ and hyperthermia in $7.8 \%$. The hypothermia and normal temperature seizures were more common in newborn $<$ one week and hyperthermia was noted in older. The associated pathologies in the context of hyperthermia were neonatal infections (17.4\%) and falciparum malaria (22.7\%) respectively in one week newborn and older. Perinatal ischaemic/hypoxic (35.5\%), falciparum malaria (13.6\%) and respiratory tract infections and gastroenteritis $(11.8 \%)$ were the main diseases associated with seizures in the context of hypothermia and normal temperature. The aetiologies were marked by neonatal brain injuries and perinatal asphyxia. Sixteen neonates with seizures were died giving a direct mortality rate of $4.7 \%$. Eight (2.3\%) surviving newborns had heavy neurodevelopmental deficits at discharge. Conclusion: The neonate seizures are an indicative of infection with or without fever. The causes of newborn convulsions must be prevented through a wide available public health programs.
\end{abstract}

Keywords: Convulsions, Etiologies, Incidence, Neonates, Temperature

\section{Introduction}

Seizures are the most common emergencies neurological conditions in the neonate. ${ }^{[1,2]}$ It occurred in $3.9 \%$ of neonates compared with $1.5 \%$ of older infants. ${ }^{[2-4]}$ The mortality rate was reported as approximately $20 \%$ to $35 \%{ }^{[5,6]}$ Neonatal seizures are an age-specific seizure syndrome and most symptomatic due to brain immature. ${ }^{[7,8]}$ These seizures differed in semiology, pathophysiology, etiology, and electroencephalographic signature and treatment compared with seizures at older ages. ${ }^{[9-12]}$ The causes were marked by hypoxic/ ischemic encephalopathy (HIE), stroke disorders, cortical malformations, infections, metabolic disturbances and benign familial neonatal convulsions. ${ }^{[9,10,13]}$ The outcome of seizures in over $30 \%$ of survival neonates were marked by neurodevelopmental and cognitive deficits and later life epilepsy. ${ }^{[3,7,14]}$

The objectives of the present research were to assess the frequency, a etiology and outcome of neonatal seizures in relationship with rectal temperature in neonates.

\section{Subjects and Methods}

\subsection{Setting}

The study was located in pediatric department of Lomé University Hospital. This center is the national referral hospital 
for children health under 15 years and it is divided into many units. The prospective study assessed newborns admitted consecutively and covered a period from $1^{\text {st }}$ January to $31^{\text {st }}$ December 2013, for seizures associated to rectal temperature.

\subsection{Neonates Assessment}

A neonate is defined as any child admitted aged 28 days or younger. Seizures were defined as reported or observed repeated involuntary muscle contractions, abnormal tonic extensions or jerky movements of any part of the limbs, face or mouth.

At admission, the neonatologist performed emergency care procedures according to the national guidelines (correction of metabolic and electrolytes unbalance) before taking a formal admission history. The history included the number and where possible, a parental description of the seizure types and interventions already offered. The physical exam was included a formal assessment of the gestational age, delivery condition. The general aspect of neonate, determination of a possible site of infection and any injuries was done.

The collected data concerned seizures features, temperature (took with rectal thermometer), umbilical aspect (redness or pus), respiratory distress, poor Apgar score scale $(<7)$ at $5 \mathrm{~min}$, feeding problems, a bulging fontanel, and consciousness status.

A venous blood sample was drawn for a full routine analysis. Hypokalaemia was defined as plasma $\mathrm{K}+<3.0 \mathrm{mmol} / \mathrm{L}$, hyperkalaemia as $\mathrm{K}+>5.0 \mathrm{mmol} / \mathrm{L}$, hyponatraemia as $\mathrm{Na}+<125 \mathrm{mmol} / \mathrm{L}$ and impaired renal function as plasma creatinine $>80 \mu \mathrm{mol} / \mathrm{L}$. Hypoglycaemia was considered if a blood glucose $<3 \mathrm{mmol} / \mathrm{L}$. Where not contraindicated, a lumbar puncture was performed in all babies admitted for seizures. All received empirical antibiotic treatment in case of suspected infection. There were no facilities to identify viral causes of meningoencephalitis and for neonate EEG recording.

Premature ( $<37$ weeks), low birth weight $(<2000$ grams), neonatal tetanus and any neonate presenting with other symptoms than seizures were excluded. The discharging clinician made the final diagnosis after review of the admission history, inpatient management notes and laboratory investigations. These diagnoses were checked by a supervising clinician neonatologist and pediatrics neurologist. The study was approved by the ethic institute of the university hospital. Parents, relatives or near misses were asked to sign the inform consent.

\section{Results}

\subsection{Seizures Frequency}

Seizures were observed in 344/4836(7.1\%). The sample included 192 males and 152 females. The seizure frequency in newborn aged $0-21$ days was $95.9 \%$ and was $52.6 \%$ in neonates $<$ one day. The focal seizures (tonic, clonic, spasms) were reported in $68 \%$ follow by generalized tonic-clonic in $24.4 \%$. Status epilepticus was observed in $7.6 \%$.

\subsection{Seizures and Rectal Temperature}

Seizures had occurred in a context of hypothermia in $77.9 \%$, normal temperature, $14.2 \%$ and hyperthermia in $7.8 \%$. The hypothermia and normal temperature seizures were more common in newborn $<$ one week and hyperthermia was noted in older.

\subsection{Seizures Risk Factors and Associated Pathologies}

The seizures risk factors were marked by laborious delivery $(39.5 \%)$, neonate aged less than one day, $(86.7 \%)$, poor Apgar score and neonatal distress (49.7\%). The associated pathologies in the context of hyperthermia were dominated by neonatal infections with bacterial meningitis (17.4\%), falciparum malaria $(22.7 \%)$ respectively in one week newborn and older. Perinatal asphyxia/hypoxic (35.5\%), falciparum malaria $(13.6 \%)$ and respiratory tract infections and gastroenteritis $(11.8 \%)$ were the main diseases associated with seizures in the context of hypothermia and normal temperature. In table I is reported the demographic, clinical and aetiologic repartition of newborns with seizures.

\subsection{Distribution of Seizures}

The months of September (51, 14.8\%), January (42, 12.2\%) and May $(40,11.6 \%)$, and the $1^{\text {st }}$ and $3^{\text {rd }}$ weeks of life respectively $(39.2 \%, 135 ; 30.8 \%, 106)$ have recorded more seizures in newborns. Table II and III had reported respectively the weekly and monthly distribution of neonatal seizures.

Sixteen neonates with seizures were died giving a global mortality rate of $3.3 \%$ and direct rate of $4.7 \%$. The mortality rate in newborns younger than one week was $6.6 \%(12)$. Eight $(2.3 \%)$ surviving newborns had gross neurodevelopmental and physical disabilities at discharge.

Table I. Demographic, clinical and etiologic distribution of newborns with seizures.

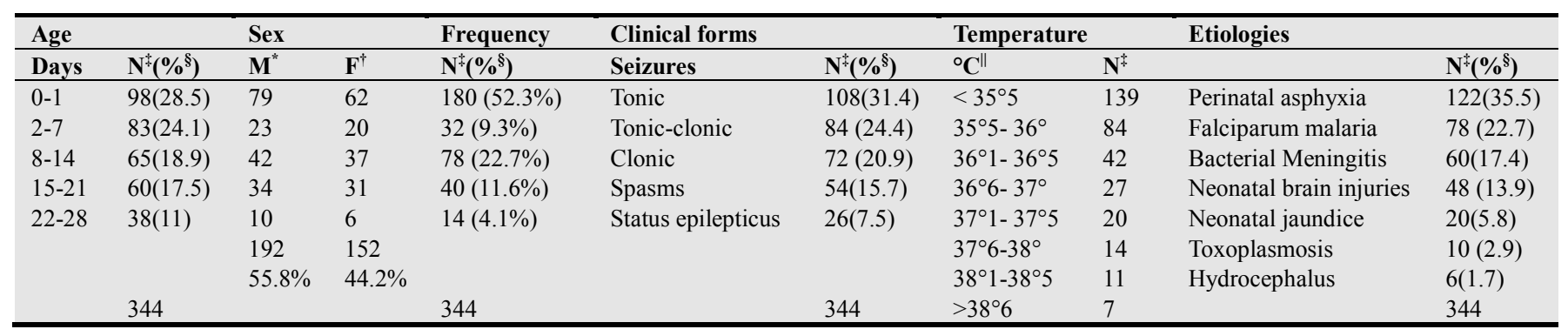

Legend: $\mathrm{M}^{*}=$ male; $\mathrm{F}^{\dagger}=$ female; $\mathrm{N}^{\dagger}=$ number; $\%{ }^{\S}=$ percentage; ${ }^{\circ} \mathrm{C}^{\|}=$Celsius degree 
Table II. Frequency of neonatal convulsions during the first four weeks of life.

\begin{tabular}{llllll}
\hline & $\mathbf{1}^{\text {st }}$ week & $\mathbf{2}^{\text {nd }}$ & $\mathbf{3}^{\text {rd }}$ & $\mathbf{4}^{\text {th }}$ & Total \\
\hline Number & 135 & 62 & 106 & 41 & 344 \\
Percentage (\%) & 39.2 & 18 & 30.8 & 12 & 100 \\
\hline
\end{tabular}

Table III. Monthly distribution of neonatal convulsions.

\begin{tabular}{|c|c|c|c|c|c|c|c|c|c|c|c|c|c|}
\hline & September & October & November & December & January & Febrary & March & April & May & June & July & August & Total \\
\hline Number & 51 & 22 & 24 & 15 & 42 & 18 & 33 & 28 & 40 & 17 & 26 & 28 & 344 \\
\hline
\end{tabular}

Legend: $\%=$ percentage

\section{Discussion}

\subsection{Methodology, Strengthen and Weakness}

The study concerned newborns aged 28 days with seizures in relationship to temperature. Some weaknesses were associated to this work. We were only able to document seizures that were clinically evident. It is possible that we missed subclinical seizures. ${ }^{[11,12]}$ Secondly, some children died being transferred process from home or basic clinic to hospital. We were unable to collect patients who could not afford care facilities or were more likely to attend basic hospitals or traditional healers. These have been the bias in the recruitment of patients. However, the consistency of our results with previous studies in the literature provides some validity to the data.

\subsection{Study Outcome}

The first and third weeks of life, and especially the first 24 hours, have emerged as the wealthiest in neonatal seizures. This hospital frequency of seizures is much lower than that reported in previous studies in the north of our country which was $26.2 \%$ fifteen years ago. ${ }^{[15]}$ This reduction may partly be the result of improved in management and especially the education of the population to change behavior towards infant's fever and convulsions. The male was prominent as reported in previous studies ranging from 55 to $56 \% .^{[9,16,17]}$ Convulsive seizures are more common in young neonate according to the immaturity of the brain. ${ }^{[4,7,18]}$ Some previous studies have reported that the incidence of that condition in poor resources setting is much higher than that reported from developed nations. This may reflect the high prevalence of risk factors for neonatal brain insult in these parts of the world. ${ }^{[1,15,17]}$

The clinical forms of neonatal seizures associated to rectal temperature can be difficult to discern as they can occur within or without fever. There are often subtle seizures given the fact that electro-clinical dissociation is more common in neonates than in other age groups. ${ }^{[6,11,12]}$ Over than $80 \%$ of EEG documented seizures were not accompanied by observable clinical seizures. ${ }^{[12,20,21]}$ These difficulties are due to immature of white matter tracts.

There is a permanent controversy regarding the dominated form of seizures in neonates. In one hand, the focal seizures are predominant in newborn and generalized tonic-clonic form in infant and child as reported in several studies. $^{[2,7,13,24,25]}$

In other hand, for some authors, the tonic-clonic generalized seizures are more common than focal seizures. ${ }^{[5,9]}$ In fact, the divergence of these data reflects the state of brain maturity at the time of the seizures. The more the child is younger, he convulses and the process of the convulsion is unclear and willingly atypical. In children older and therefore more mature brain, tonic-clonic seizures go according to conventional neuron pathways.

The most two common diagnoses associated with neonatal seizures were infections (malaria and meningitis) and neonatal encephalopathy. Both conditions are preventable by using simple public health interventions. These measures are pregnancy surveillance, safe deliveries, appropriate neonatal resuscitation, and prevention and early treatment of neonatal infections. ${ }^{[26-28]}$ Febrile and non febrile seizures are the main condition in newborn to manifest infection. The hypothermic convulsions are mainly due to HIE by perinatal asphyxia, neonate infection and familial epilepsy. The main diseases associated with febrile seizures were severe malaria and bacterial meningitis as reported by several authors. ${ }^{[5,9,30,31]}$ In none endemic-malaria countries, febrile seizures are often due to nasopharyngeal and respiratory tract infections, and eruptive fevers or gastroenteritis. ${ }^{[4,10,24]}$ Fifteen percent of all newborns with seizures had neurological impairment at discharge. ${ }^{[16,22]}$ The long term outcome is marked by neurodevelopmental retardation, behavioral disturbance and epilepsy and is largely depended on the cause of the seizure. $^{[9,11,25]}$

\section{Conclusion}

The early management of fetal distress and the strengthening of neonatologist, obstetrician and wise wives capacities can help to prevent brain injuries and its related events in neonate later life. These vital measures must be disseminated through a large public health program to basic health structures.

\section{References}

[1] Mwaniki M, Mathenge A, Gwer S, Mturi N, Bauni E, Newton CRJC, et al. Neonatal seizures in a rural Kenyan District Hospital: Aetiology, Incidence and Outcome of hospitalization. BMC Medicine 2010;8:16-23. 
[2] Ronen GM, Penney S, Andrews W. The epidemiology of clinical neonatal seizures in Newfoundland: a populationbased study. J. Pediatr 1999; 134:71-5.

[3] Jensen FE. Neonatal Seizures: An Update on Mechanisms and Management. Clin Perinatol. 2009; 36:881-900.

[4] Silverstein FS, Jensen FE. Neonatal seizures. Ann Neurol 2007;62:112-20.

[5] Abdou Raouf O, Tchoua RK, Ndinga JP, Guikoumbi JR, Josseaume A, Tchoua R. Paediatric emergencies at Libreville University Hospital. Méd. d'Afrique Noire 2002;49:475-80.

[6] Lawn JE, Wilczynska-Ketende K, Cousens SN. Estimating the causes of 4 millions neonatal deaths in the year 2000. Int $J$ Epidemiol 2006; 35:706-18.

[7] Schmitt B, Wohlrab G, Sander T, Steinlein OK, Hajnal BL. Neonatal seizures with tonic clonic sequences and poor developmental outcome. Epilepsy Res 2005; 65: 161-8.

[8] Scher MS. Neonatal seizure classification: a fetal perspective concerning childhood epilepsy. Epilepsy Res 2006; 70 Suppl $1:$ S41-57.

[9] Tekgul H, Gauvreau K, Soul J, Murphy L, Robertson R, Stewart J, et al. The current etiologic profile and neurodevelopmental outcome of seizures in term newborn infants. Pediatrics 2006;117:1270-80.

[10] Sankar R, Painter MJ. Neonatal seizures: after all these years we still love what doesn't work. Neurology 2005;64:776-777.

[11] Kumar A, Gupta A, Talukdar B. Clinico-etiological and EEG profile of neonatal seizures. Indian J Pediatr 2007;74:33-7.

[12] Murray DM, Ryan CA, Boylan GB, Fitzgerald AP, Connolly S. Prediction of seizures in asphyxiated neonates: correlation with continuous video electroencephalographic monitoring. Pediatrics 2006;118:41-6.

[13] Pellock JM. Understanding co-morbidities affecting children with epilepsy. Neurology $2004 ; 62: 17-23$.

[14] Idro R, Gwer S, Kahindi M, Gatakaa H, Kazungu T, Ndiritu M, et al. The incidence, aetiology and outcome of acute seizures in children admitted to a rural Kenyan district hospital. $B M C$ Pediatr 2008;8:5-15.

[15] Agbèrè $\mathrm{AD}$, Tatagan $\mathrm{K}$, Madikorai MG, Eklu-Avlasu E, Balaka B, Bakondé B, et al. Infant convulsive seizures in the pediatric service of Kara Regional Hospital (North-Togo). Méd Afr Noire 1995;42:310-4.

[16] Gebremariam A, Gutema Y, Leuel A, Fekadu H. Early-onset neonatal seizures: types, risk factors and short-term outcome. Ann Trop Paediatr 2006;26:127-31.
[17] Birbeck GL. Seizures in rural Zambia. Epilepsia 2000;41:27781.

[18] Pisani F, Cerminara C, Fusco C, Sisti L. Neonatal status epilepticus vs recurrent neonatal seizures: clinical findings and outcome. Neurology 2007;69:2177-85.

[19] Saliba RM, Annegers JF, Waller DK, Tyson JE, Mizrahi EM. Incidence of neonatal seizures in Harris County, Texas, 19921994. Am. J Epidemiol 1999;150:763-9.

[20] Toet MC, Groenendaal F, Osredkar D, van Huffelen AC, de Vries LS. Post neonatal epilepsy following amplitudeintegrated EEG-detected neonatal seizures. Pediatr Neurol 2005;32:241-7.

[21] Scher MS, Aso K, Beggarly ME, Hamid MY, Steppe DA, Painter MJ, et al. Electrographic seizures in preterm and fullterm neonates: clinical correlates, associated brain lesions and risk for neurologic sequelae. Pediatrics 1993;91:128-34

[22] Ronen GM, Buckley D, Penney S, Streiner DL. Long-term prognosis in children with neonatal seizures: a populationbased study. Neurology 2007;69:1816-22.

[23] Hauser WA. The prevalence and incidence of convulsive disorders in children. Epilepsia 1994;35 Suppl 2:S1-6.

[24] Kriouile Y, Mdaghri AA, Hamdani S, Lamdouar BN. Neonatal convulsions: A study of 71 cases. Rev. Maghr. Pédiatr. 1999; 9:141-6.

[25] Pisani F, Sisti L, Seri S. A scoring system for early prognostic assessment after neonatal seizures. Pediatrics 2009;124:580-7.

[26] Rennie JM, Boylan GB. Neonatal seizures and their treatment. Curr Opin Neurol 2003; 16:177-81.

[27] Hellstrom WL, Blennow G, Lindroth M, Rosen I, Svenningsen NW. Low risk of seizure recurrence after early withdrawal of antiepileptic treatment in the neonatal period. Arch. Dis. Child.1995;72:F97-101.

[28] Musoke RN, Malenga GJ. Bacterial infections in neonates at the Kenyatta Hospital Nursery. A prospective study. East Afr Med $J$ 1984;61:909-16.

[29] Lanska MJ, Lanska DJ. Neonatal seizures in the United States: results of the National Hospital Discharge Survey, 1980-1991. Neuroepidemiology 1996;15:117-25.

[30] Ghedira-Besbes L, Fattaki S, Ben Meriem Ch, Chouchene S, Nouri S, Haddad S, et al. Febrile seizures in infant: A study of 511 cases. Rev. Maghr. pédiatr 2004;14:171-9.

[31] Sadleir LG, Scheffer IE. Febrile seizures. BMJ 2007; 334:30711. 